Article

\title{
Eco-Friendly Synthesis and Antiproliferative Evaluation of Some Oxygen Substituted Diaryl Ketones
}

\author{
Paola Arenas ${ }^{1}$, Andrés Peña ${ }^{1}$, David Ríos ${ }^{1,2}$, Julio Benites ${ }^{1,2, *}$, Giulio G. Muccioli ${ }^{3}$, \\ Pedro Buc Calderon ${ }^{1,2,4}$ and Jaime A. Valderrama ${ }^{1,2,5, *}$
}

1 Facultad de Ciencias de la Salud, Universidad Arturo Prat, Casilla 121, Iquique 1100000, Chile

2 Instituto de EtnoFarmacología (IDE), Universidad Arturo Prat, Casilla 121, Iquique 1100000, Chile

3 Bioanalysis and Pharmacology of Bioactive Lipids Laboratory, Louvain Drug Research Institute, Université Catholique de Louvain, 72 Avenue E. Mounier, BPBL 7201, 1200 Brussels, Belgium

4 Toxicology and Cancer Biology Research Group, Louvain Drug Research Institute, Université Catholique de Louvain, 73 Avenue E. Mounier, GTOX 7309, 1200 Brussels, Belgium

5 Facultad de Química, Pontificia Universidad Católica de Chile, Casilla 306, Santiago 6094411, Chile

* Authors to whom correspondence should be addressed; E-Mails: julio.benites@unap.cl (J.B.); jvalderr@uc.cl (J.A.V.); Tel.: +56-57-252-6215 (J.B.); Fax: +56-57-2252-6395 (J.B.).

Received: 26 June 2013; in revised form: 5 August 2013 / Accepted: 12 August 2013 /

Published: 16 August 2013

\begin{abstract}
A broad variety of oxygen-substituted diaryl ketones has been synthesized by solar energy-induced Friedel Crafts acylations of 1,4-benzo- and 1,4-naphthoquinones with benzaldehydes. The in vitro antiproliferative properties of the photoproducts were assessed on prostate (DU-145), bladder (T24) and breast (MCF7) human-derived tumor cell lines and compared to non-tumor mouse fibroblasts (Balb/3T3). Among the tested compounds, it was found that those containing a 3,4,5-trimethoxyphenyl A-ring, such as $\mathbf{1 2}$ and $\mathbf{2 2}$ are more active on DU-145, with $\mathrm{EC}_{50}$ values of 1.2 and $5.9 \mu \mathrm{M}$, respectively. By comparing their effects on the three cancer cell lines, the analogue $\mathbf{2 2}$ has the best mean selective index (2.4).
\end{abstract}

Keywords: photo-Friedel Crafts acylation; diaryl ketones; green chemistry; antiproliferative activity 


\section{Introduction}

Acylhydroquinones are valuable building blocks of natural [1-4] and synthetic compounds endowed with a variety of biological properties [5-20]. The classic procedures to construct the diaryl ketone framework of acylhydroquinones are based on the Friedel Crafts acylation and Fries rearrangement. Despite the efficiency of these synthetic methods, they have some disadvantages such as the lack of atom economy, the use of hazardous environmental Lewis acids, namely $\mathrm{BF}_{3}, \mathrm{AlCl}_{3}$, $\mathrm{TiCl}_{4}$, or $\mathrm{ZnCl}_{2}$ [21-26], and limitations regarding the use of precursors containing oxygen acid-labile functional groups. The photo-Friedel Crafts acylation of quinones with aliphatic and aromatic aldehydes to prepare acylhydroquinones is a green and efficient alternative method with respect to the classic aforementioned acylation methods. It is noteworthy that several examples of the preparation of acylhydroquinones by photoacylation of 1,4-quinone with aldehydes have been reported [27-34], however, the scope of this method to the synthesis of oxygen-substituted diaryl ketones had received relatively little attention.

Among the broad variety of synthetic diaryl ketones the oxygen-substituted members, named phenstatin [35] and naphthylphenstatin [36] (Figure 1), stand out by their biological activity as microtubule-targeting agents. Based on these precedents we wanted to examine the synthetic flexibility of the eco-friendly solar photoacylation of 1,4-benzo- and 1,4-naphthoquinone with substituted benzaldehydes to the synthesis of diverse oxygen-substituted diaryl ketones. Taking advantage of this potentially simple access to oxygen-substituted diaryl ketones we were also interested in evaluating the series for in vitro antiproliferative activity on cancer cells. The aim of this study is mainly directed towards broadening the use of simple and eco-friendly methodologies in the synthesis of new oxygen-substituted diaryl ketones as well as to contribute to the search for new biological active members of this series.

Figure 1. Structure of phenstatin and naphthylphenstatin.<smiles>COc1ccc(C(=O)c2cc(OC)c(OC)c(OC)c2)cc1O</smiles>

phenstatin<smiles>COc1cc(C(=O)c2ccc3ccccc3c2)cc(OC)c1OC</smiles>

naphthylphenstatin

\section{Results and Discussion}

\subsection{Chemistry}

Based on our experience on the synthesis of heteroaroylhydroquinones by solar photoacylation of 1,4-benzo- and 1,4-naphthoquinone 1 and $\mathbf{2}$ with heteroarylcarbaldehydes in benzene [33], we initially examined the reaction of $\mathbf{1}$ and $\mathbf{2}$ with mono-substituted benzaldehydes. The reactions were carried out by using a 6.5 molar excess of the aldehyde with respect to the quinone. It is interesting to point out that molar excess of aldehyde is used to inhibit the dimerization of the quinone [30]. To avoid the use of hazardous benzene as the solvent, both the reaction of $\mathbf{1}$ and $\mathbf{2}$ with benzaldehyde and the liquid isomers of methyl- and methoxybenzaldehydes were accomplished using the appropriate aldehyde in 
excess as the solvent. In these experiments, performed by solar irradiation for 30 hours, the reaction mixtures were further submitted to column chromatography to give the respective photoproducts $3-\mathbf{8}$ and 14-18 (Scheme 1) in the 34\%-77\% yield range (Table 1). The formation yields of the products were determined on the basis of the initial and the amounts of the respective quinones recovered.

In parallel experiments, the above reactions were run in benzene in order to compare the yields of the photo-acylation reactions with and without this solvent. The results of these assays are collected in Table 1. The data indicate that the photoacylation reactions of quinones $\mathbf{1}$ and $\mathbf{2}$ give higher yields in benzene solvent than in excess aldehyde.

Scheme 1. Photoacylation of quinones 1 and $\mathbf{2}$ with substituted benzaldehydes.<smiles>[R]Cc1cc([R])c([R])c([R])c1C=C</smiles><smiles>O=C1C=CC(=O)c2ccccc21</smiles>

1,2

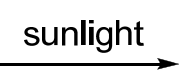

3-23

The photoacylation of quinones $\mathbf{1}$ and $\mathbf{2}$ with the solid di- and trisubstituted benzaldehydes were carried out in benzene under the above mentioned solar irradiation conditions. The treatment provides access to the corresponding photoproducts 9-13 and 19-23 in good yields (Table 1). The new diaryl ketones 7, 9-13, 15, 19-21 and 23 were fully characterized by IR, ${ }^{1} \mathrm{H}-,{ }^{13} \mathrm{C}-\mathrm{NMR}$ and HRMS.

The synthesis of compounds 4 (65\%), 6 (79\%), $8(77 \%), 14(57 \%)$ and $16(70 \%)$ have been previously reported by photoacylation of 1 and $\mathbf{2}$ with the respective aldehydes in the presence of catalytic amounts of benzophenone and using artificial light irradiation [29]. According to the data in Table 1 better yields on these compounds are achieved by using the solar chemical procedure (method B). Selected indoor photoacylation experiments performed in benzene by using irradiation with fluorescent lamps indicate that the photoproducts were generated in low yields.

Table 1. Oxygen-substituted diaryl ketones 3-23 prepared by solar photoacylation.<smiles>[R]c1cc(C(=O)c2cc(O)ccc2O)c([R])c([R])c1[R]</smiles>

3-13<smiles>[R]c1cc(C(=O)c2cc(O)c3ccccc3c2O)c([R])c([R])c1[R]</smiles>

14-23 
Table 1. Cont.

\begin{tabular}{|c|c|c|c|c|c|c|}
\hline \multirow[b]{2}{*}{ Photoproduct } & \multicolumn{4}{|c|}{ Substituents } & \multicolumn{2}{|c|}{ Yield (\%) ${ }^{a}$} \\
\hline & $\mathrm{R}^{1}$ & $\mathrm{R}^{2}$ & $\mathrm{R}^{3}$ & $\mathrm{R}^{4}$ & Method A $^{b}$ & Method B $^{\mathrm{c}}$ \\
\hline 3 & $\mathrm{H}$ & $\mathrm{H}$ & $\mathrm{H}$ & $\mathrm{H}$ & 77 & 91 \\
\hline 4 & $\mathrm{Me}$ & $\mathrm{H}$ & $\mathrm{H}$ & $\mathrm{H}$ & 52 & 80 \\
\hline 5 & $\mathrm{H}$ & $\mathrm{Me}$ & $\mathrm{H}$ & $\mathrm{H}$ & 34 & 74 \\
\hline 6 & $\mathrm{H}$ & $\mathrm{H}$ & $\mathrm{Me}$ & $\mathrm{H}$ & 58 & 82 \\
\hline 7 & $\mathrm{H}$ & $\mathrm{OMe}$ & $\mathrm{H}$ & $\mathrm{H}$ & 38 & 74 \\
\hline 8 & $\mathrm{H}$ & $\mathrm{H}$ & $\mathrm{OMe}$ & $\mathrm{H}$ & 59 & 79 \\
\hline 9 & $\mathrm{OMe}$ & $\mathrm{H}$ & $\mathrm{H}$ & $\mathrm{OMe}$ & - & 70 \\
\hline 10 & $\mathrm{H}$ & $\mathrm{H}$ & $\mathrm{OMe}$ & $\mathrm{OMe}$ & - & 70 \\
\hline 11 & $\mathrm{H}$ & $\mathrm{OMe}$ & $\mathrm{OH}$ & $\mathrm{H}$ & - & 78 \\
\hline 12 & $\mathrm{H}$ & $\mathrm{OMe}$ & $\mathrm{OMe}$ & $\mathrm{OMe}$ & - & 70 \\
\hline 13 & $\mathrm{H}$ & $\mathrm{OMe}$ & $\mathrm{OH}$ & $\mathrm{OMe}$ & - & 70 \\
\hline 14 & $\mathrm{Me}$ & $\mathrm{H}$ & $\mathrm{H}$ & $\mathrm{H}$ & 53 & 82 \\
\hline 15 & $\mathrm{H}$ & $\mathrm{Me}$ & $\mathrm{H}$ & $\mathrm{H}$ & 41 & 69 \\
\hline 16 & $\mathrm{H}$ & $\mathrm{H}$ & $\mathrm{Me}$ & $\mathrm{H}$ & 57 & 84 \\
\hline 17 & $\mathrm{H}$ & $\mathrm{OMe}$ & $\mathrm{H}$ & $\mathrm{H}$ & 50 & 71 \\
\hline 18 & $\mathrm{H}$ & $\mathrm{H}$ & $\mathrm{OMe}$ & $\mathrm{H}$ & 69 & 88 \\
\hline 19 & $\mathrm{OMe}$ & $\mathrm{H}$ & $\mathrm{H}$ & $\mathrm{OMe}$ & - & 65 \\
\hline 20 & $\mathrm{H}$ & $\mathrm{H}$ & $\mathrm{OMe}$ & $\mathrm{OMe}$ & - & 63 \\
\hline 21 & $\mathrm{H}$ & $\mathrm{H}$ & $\mathrm{OH}$ & $\mathrm{OMe}$ & - & 73 \\
\hline 22 & $\mathrm{H}$ & $\mathrm{OMe}$ & $\mathrm{OMe}$ & $\mathrm{OMe}$ & - & 60 \\
\hline 23 & $\mathrm{H}$ & $\mathrm{OMe}$ & $\mathrm{OH}$ & $\mathrm{OMe}$ & - & 66 \\
\hline
\end{tabular}

${ }^{a}$ Isolated by column chromatography; ${ }^{b}$ Method A: the reaction was carried out using 1 or 2 (1 equiv.) and the aldehyde ( 7.5 equiv.) without benzene; ${ }^{\mathrm{c}}$ Method B: the reaction was carried out using 1 or $\mathbf{2}$ (1 equiv.), the aldehyde ( 7.5 equiv.) and benzene as the solvent.

\subsection{In Vitro Antiproliferative Activity of Diaryl Ketones 3-23 again Select Cancer Cell Lines}

The oxygen-substituted diaryl ketones 3-23 were evaluated for their in vitro antiproliferative activity on a panel of four cell lines, including non-tumor fibroblasts (Balb/3T3) and three human-derived tumor cell lines, namely DU-145 (prostate), T24 (bladder) and MCF7 (breast), using the conventional microculture tetrazolium reduction assay [37].

Table 2. In vitro inhibitory effect of compounds 3-23 on the proliferation of the human-derived tumor cell lines: T24 (bladder), DU-145 (prostate) and MCF7 (breast) and the non-tumor fibroblasts (Balb/3T3).<smiles>[R]c1cc(C(=O)c2cc(O)ccc2O)c([R])c([R])c1[R]</smiles>

3-13<smiles>[R]c1cc(C(=O)c2cc(O)c3ccccc3c2O)c([R])c([R])c1[R]</smiles>

14-23 
Table 2. Cont.

\begin{tabular}{|c|c|c|c|c|c|c|c|c|c|}
\hline \multirow[b]{2}{*}{$\mathbf{N}^{\circ}$} & \multirow[b]{2}{*}{$\mathbf{R}^{1}$} & \multirow[b]{2}{*}{$\mathbf{R}^{2}$} & \multirow[b]{2}{*}{$\mathbf{R}^{3}$} & \multicolumn{6}{|c|}{$\operatorname{EC}_{50} \pm \operatorname{SEM}^{a}(\mu M)$} \\
\hline & & & & $\mathbf{R}^{4}$ & $\mathbf{T} 24$ & DU-145 & MCF-7 & BALB/3T3 & MSI $^{b}$ \\
\hline 3 & $\mathrm{H}$ & $\mathrm{H}$ & $\mathrm{H}$ & $\mathrm{H}$ & $186.4 \pm 20.4$ & $205.0 \pm 21.5$ & $189.8 \pm 19.2$ & $38.5 \pm 5.5$ & 0.20 \\
\hline 4 & $\mathrm{Me}$ & $\mathrm{H}$ & $\mathrm{H}$ & $\mathrm{H}$ & $172.5 \pm 13.2$ & $172.5 \pm 19.7$ & $180.7 \pm 15.8$ & $183.9 \pm 17.6$ & 1.06 \\
\hline 5 & $\mathrm{H}$ & $\mathrm{Me}$ & $\mathrm{H}$ & $\mathrm{H}$ & $202.3 \pm 15.9$ & $186.2 \pm 17.8$ & $225.7 \pm 24.2$ & $100.3 \pm 9.5$ & 0.49 \\
\hline 6 & $\mathrm{H}$ & $\mathrm{H}$ & $\mathrm{H}$ & $\mathrm{Me}$ & $208.9 \pm 19.5$ & $100.8 \pm 9.5$ & $142.1 \pm 15.3$ & $78.3 \pm 6.4$ & 0.57 \\
\hline 7 & $\mathrm{H}$ & $\mathrm{OMe}$ & $\mathrm{H}$ & $\mathrm{H}$ & $209.7 \pm 20.5$ & $166.1 \pm 15.8$ & $154.4 \pm 12.3$ & $117.6 \pm 19.5$ & 0.68 \\
\hline 8 & $\mathrm{H}$ & $\mathrm{H}$ & $\mathrm{OMe}$ & $\mathrm{H}$ & $168.1 \pm 12.2$ & $170.2 \pm 15.5$ & $190.7 \pm 17.5$ & $85.2 \pm 9.7$ & 0.49 \\
\hline 9 & $\mathrm{OMe}$ & $\mathrm{H}$ & $\mathrm{H}$ & $\mathrm{OMe}$ & $149.7 \pm 18.4$ & $130.3 \pm 12.5$ & $164.5 \pm 13.8$ & $43.7 \pm 7.6$ & 0.29 \\
\hline 10 & $\mathrm{H}$ & $\mathrm{H}$ & $\mathrm{OMe}$ & $\mathrm{OMe}$ & $147.4 \pm 19.2$ & $140.0 \pm 13.6$ & $182.9 \pm 17.7$ & $35.4 \pm 4.7$ & 0.23 \\
\hline 11 & $\mathrm{H}$ & $\mathrm{OMe}$ & $\mathrm{OH}$ & $\mathrm{H}$ & $154.5 \pm 14.5$ & $167.5 \pm 15.9$ & $176.7 \pm 19.4$ & $78.0 \pm 9.3$ & 0.47 \\
\hline 12 & $\mathrm{H}$ & $\mathrm{OMe}$ & $\mathrm{OMe}$ & $\mathrm{OMe}$ & $3.6 \pm 1.4$ & $1.2 \pm 0.6$ & $53.6 \pm 6.7$ & $1.5 \pm 0.4$ & 0.57 \\
\hline 13 & $\mathrm{H}$ & $\mathrm{OMe}$ & $\mathrm{OH}$ & $\mathrm{OMe}$ & $>350$ & $112.8 \pm 10.7$ & $>350$ & $19.1 \pm 3.1$ & - \\
\hline 14 & $\mathrm{Me}$ & $\mathrm{H}$ & $\mathrm{H}$ & $\mathrm{H}$ & $143.3 \pm 9.5$ & $143.8 \pm 17.7$ & $152.3 \pm 14.5$ & $225.5 \pm 25.4$ & 1.54 \\
\hline 15 & $\mathrm{H}$ & $\mathrm{Me}$ & $\mathrm{H}$ & $\mathrm{H}$ & $136.8 \pm 11.7$ & $147.4 \pm 15.9$ & $144.9 \pm 12.7$ & $142.4 \pm 13.9$ & 0.99 \\
\hline 16 & $\mathrm{H}$ & $\mathrm{H}$ & $\mathrm{Me}$ & $\mathrm{H}$ & $134.6 \pm 12.8$ & $158.3 \pm 13.7$ & $133.8 \pm 14.9$ & $138.9 \pm 15.2$ & 0.98 \\
\hline 17 & $\mathrm{H}$ & $\mathrm{OMe}$ & $\mathrm{H}$ & $\mathrm{H}$ & $133.3 \pm 12.4$ & $139.4 \pm 11.3$ & $127.9 \pm 13.6$ & $109.1 \pm 11.1$ & 0.82 \\
\hline 18 & $\mathrm{H}$ & $\mathrm{H}$ & $\mathrm{OMe}$ & $\mathrm{H}$ & $126.8 \pm 10.6$ & $77.5 \pm 6.5$ & $124.9 \pm 10.2$ & $107.0 \pm 12.3$ & 1.03 \\
\hline 19 & $\mathrm{OMe}$ & $\mathrm{H}$ & $\mathrm{H}$ & $\mathrm{OMe}$ & $129.8 \pm 10.1$ & $128.7 \pm 17.2$ & $>310$ & $100.3 \pm 8.9$ & 0.77 \\
\hline 20 & $\mathrm{H}$ & $\mathrm{H}$ & $\mathrm{OMe}$ & $\mathrm{OMe}$ & $46.8 \pm 5.1$ & $61.8 \pm 5.6$ & $12.2 \pm 3.8$ & $2.8 \pm 0.6$ & 0.11 \\
\hline 21 & $\mathrm{H}$ & $\mathrm{H}$ & $\mathrm{OH}$ & $\mathrm{OMe}$ & $86.6 \pm 9.6$ & $89.0 \pm 7.3$ & $15.7 \pm 4.6$ & $15.7 \pm 3.9$ & 0.45 \\
\hline 22 & $\mathrm{H}$ & $\mathrm{OMe}$ & $\mathrm{OMe}$ & $\mathrm{OMe}$ & $13.5 \pm 1.9$ & $5.9 \pm 0.8$ & $20.2 \pm 4.5$ & $25.1 \pm 3.9$ & 2.45 \\
\hline 23 & $\mathrm{H}$ & $\mathrm{OMe}$ & $\mathrm{OH}$ & $\mathrm{OMe}$ & $112.0 \pm 9.3$ & $113.5 \pm 9.5$ & $130.2 \pm 14.8$ & $99.6 \pm 7.5$ & 0.84 \\
\hline $\mathrm{DOX}^{\mathrm{c}}$ & - & - & - & - & $0.65 \pm 0.07$ & $0.42 \pm 0.03$ & $0.33 \pm 0.05$ & $0.19 \pm 0.01$ & 0.44 \\
\hline $\mathrm{MIT}^{\mathrm{d}}$ & - & - & - & - & $42.2 \pm 5.8$ & $14.3 \pm 2.6$ & $16.8 \pm 2.9$ & $27.3 \pm 3.3$ & 1.39 \\
\hline
\end{tabular}

Table 2 summarizes the data from these evaluations: it shows the $\mathrm{EC}_{50}$ values $(\mu \mathrm{M})$ of the respective benzo- and naphthohydroquinone derivatives. These values were calculated from their effects on MTT reduction in three cancer cell lines and Balb/3T3 non transformed mouse fibroblasts as a function of their concentration during $48 \mathrm{~h}$ of incubation. All three cancer cell lines were similarly sensitive to these compounds. With rather few exceptions, the members containing the dihydroxyphenyl fragment, such as 3-13, were in general less active than their corresponding naphthyl analogues 14-23 when tested against cancer cells, but just the opposite was observed in non-transformed fibroblasts. The data in Table 2 showed that compounds $\mathbf{1 2}$ and $\mathbf{2 2}$ appear as the most potent members of the series with lower $\mathrm{EC}_{50}$ values against $\mathrm{T} 24$ and DU-145 with respect to the reference drug mitomycin $\mathrm{C}$. The biological activity differences of compounds $\mathbf{1 2}$ and 22 with respect to their analogues could be attributed to the 3,4,5-trimethoxy substitution on the A-phenyl ring. According to literature precedents, the 3,4,5-trimethoxyphenyl ring is considered essential for the antitubulin activity of a broad variety of antimitotic compounds [36,38-45]. Nevertheless, it should be noted that the $\mathrm{EC}_{50}$ values of compounds $\mathbf{1 2}$ and $\mathbf{2 2}$ are two orders of magnitude lower than to that reported to phenstatin when tested in the NCI screen [35] showing a mean panel GI $_{50}$ (growth inhibitory) value of $6.01 \times 10^{-8} \mathrm{M}$. In addition to the tendency showing that dihydroxynaphthyl 
analogues are more active than the dihydroxyphenyl derivatives, the vast majority of compounds did not have an adequate selectivity (Table 2), that is they affect both cancer and non-tumor cells in a similar way. In this context, only compound 22 have a good mean selectivity index (2.45).

\section{Experimental}

\subsection{General}

All reagents were commercially available reagent grade and were used without further purification. Melting points were determined on a Stuart Scientific SMP3 apparatus and are uncorrected. The IR spectra were recorded on an FT Bruker spectrophotometer using $\mathrm{KBr}$ disks, and the wave numbers are given in $\mathrm{cm}^{-1}$. ${ }^{1} \mathrm{H}-\mathrm{NMR}$ spectra were run on Bruker AM-200 and AM-400 instruments in deuterochloroform $\left(\mathrm{CDCl}_{3}\right)$ and dimethyl sulfoxide- $\mathrm{d}_{6}\left(\mathrm{DMSO}-d_{6}\right)$. Chemical shifts are expressed in ppm downfield relative to tetramethylsilane (TMS, $\delta$ scale), and the coupling constants $(J)$ are reported in Hertz. ${ }^{13} \mathrm{C}-\mathrm{NMR}$ spectra were obtained in $\mathrm{CDCl}_{3}+\mathrm{DMSO}-d_{6}$ at 50 and $100 \mathrm{MHz}$. Chemical shifts are reported in $\delta \mathrm{ppm}$ downfield from TMS, and $J$-values are given in Hertz. HRMS data were obtained on Thermo Finnigan mass spectrometer, model MAT 95XP and LTQ-Orbitrap mass spectrometer (Thermo-Fisher Scientific) with the analysis performed using an APCI source operated in positive mode. Silica gel Merck 60 (70-230 mesh) was used for preparative column chromatography and TLC aluminum foil $60 \mathrm{~F}_{254}$ for analytical TLC. The solar irradiation experiments were performed at the Canchones Experimental Center in Iquique/Chile (latitude 20²6'43.80"S, $990 \mathrm{~m}$ above sea level), located in the Atacama Desert.

\subsection{Chemistry}

General Procedure for Photoacylation of $\mathbf{1}$ and $\mathbf{2}$ with Substituted Benzaldehydes in the Absence of Benzene (Method A)

Quinone 1 or $2(1 \mathrm{mmol})$ and the liquid aldehyde $(7.5 \mathrm{mmol})$, were placed into a test tube, nitrogen was bubbled through the solution for $2 \mathrm{~min}$ and then the tube was sealed with a septum. The mixture was irradiated for six days (total illumination time of $30 \mathrm{~h}$ ), under solar radiation conditions in the range 800-1100 Watts $/ \mathrm{m}^{2}$ (November-March). The mixture reaction was chromatographed on silica gel (3:1 petroleum ether/ethyl acetate) to give pure samples of the corresponding diaryl ketones. The remaining precursors were recovered to be used in further preparations.

General Procedure for Photoacylation of 1 and $\mathbf{2}$ with Substituted Benzaldehydes in Benzene (Method B).

A $100 \mathrm{~mL}$ benzene solution of the required quinone $\mathbf{1}$ or $\mathbf{2}(1 \mathrm{mmol})$ and the substituted benzaldehyde $(7.5 \mathrm{mmol})$, was placed into the outer jacket of a Liebig condenser type. The solution was bubbled with nitrogen ( $2 \mathrm{~min}$ ), the flask was sealed with a septum and then irradiated for six days (total illumination time of $30 \mathrm{~h}$ ), under solar radiation conditions in the range $800-1100 \mathrm{Watts} / \mathrm{m}^{2}$ (November-March). The solvent was evaporated under reduced pressure and the residue was 
chromatographed on silica gel (3:1 petroleum ether/ethyl acetate). The starting aldehyde and the solvent were recovered and employed in the next batches.

(2,5-Dihydroxyphenyl)(phenyl)methanone (3). This compound was prepared from quinone $\mathbf{1}$ and benzaldehyde and was isolated in 77 and $91 \%$ yield by following methods A and B, respectively; orange solid, mp $121-122{ }^{\circ} \mathrm{C}$ (lit. [46]: $125-126^{\circ} \mathrm{C}$ ). IR (KBr) $v_{\text {máx }} \mathrm{cm}^{-1}$ : $3456(\mathrm{O}-\mathrm{H}), 3358(\mathrm{O}-\mathrm{H})$, $1637(\mathrm{C}=\mathrm{O}) ;{ }^{1} \mathrm{H}-\mathrm{NMR}\left(\mathrm{CDCl}_{3}\right): \delta 6.98\left(\mathrm{~m}, 2 \mathrm{H}, 4^{\prime}-\mathrm{H}+5-\mathrm{OH}\right), 7.03(\mathrm{~s}, 1 \mathrm{H}, 6-\mathrm{H}), 7.11(\mathrm{~d}, 2 \mathrm{H}, J=7.2 \mathrm{~Hz}$, $\left.2^{\prime}-\mathrm{H}+6^{\prime}-\mathrm{H}\right), 7.19\left(\mathrm{~m}, 2 \mathrm{H}, 3^{\prime}-\mathrm{H}+5^{\prime}-\mathrm{H}\right), 8.10(\mathrm{~d}, 1 \mathrm{H}, J=7.8 \mathrm{~Hz}, 3-\mathrm{H}$ or $4-\mathrm{H}), 8.21(\mathrm{~d}, 1 \mathrm{H}, J=7.8 \mathrm{~Hz}$, $4-\mathrm{H}$ or $3-\mathrm{H}), 11.42$ (bs $1 \mathrm{H}, 2-\mathrm{OH}) ;{ }^{13} \mathrm{C}-\mathrm{NMR}\left(\mathrm{CDCl}_{3}\right): \delta 119.6,119.9,123.4,125.5,129.1,129.5$, $129.7,130.4,130.6,132.7,138.9,149.9,206.1$; HRMS $\left(\mathrm{M}^{+}\right): m / z$ calcd for $\mathrm{C}_{13} \mathrm{H}_{10} \mathrm{O}_{3}: 214.06299$; found: 214.06189 .

(2,5-Dihydroxyphenyl)(2'-methylphenyl)methanone (4). This compound was prepared from quinone $\mathbf{1}$ and 2-methylbenzaldehyde in 52 and $80 \%$ yield following methods $\mathrm{A}$ and $\mathrm{B}$, respectively; yellow solid, mp 104-105 ${ }^{\circ} \mathrm{C}$ (lit. [47]: 106-108 ${ }^{\circ} \mathrm{C}$ ). IR (KBr) v $v_{\text {máx }} \mathrm{cm}^{-1}: 3287(\mathrm{O}-\mathrm{H}), 1638(\mathrm{C}=\mathrm{O}) ;{ }^{1} \mathrm{H}-\mathrm{NMR}$ $\left(\mathrm{CDCl}_{3}\right): \delta 2.29(\mathrm{~s}, 3 \mathrm{H}, \mathrm{Me}), 4.76(\mathrm{~s}, 1 \mathrm{H}, 5-\mathrm{OH}), 6.71(\mathrm{~d}, 1 \mathrm{H}, J=3.0 \mathrm{~Hz}, 6-\mathrm{H}), 6.95(\mathrm{~d}, 1 \mathrm{H}, J=8.9 \mathrm{~Hz}$, 3-H), 7.04 (dd, 1H, J = 8.9, 3.0 Hz, 4-H), 7.27 (m, 3H, 3'-H + 4'-H + 6'-H), 7.39 (m, 1H, 5'-H), 11.81 (s, 1H, 2-OH); ${ }^{13} \mathrm{C}-\mathrm{NMR}\left(\mathrm{CDCl}_{3}\right): \delta 19.6,118.1,119.3,119.5,125.4,125.5,127.3,130.2,130.9$, 135.4, 137.7, 147.4, 157.5, 203.9; HRMS $\left(\mathrm{M}^{+}\right): \mathrm{m} / z$ calcd for $\mathrm{C}_{14} \mathrm{H}_{12} \mathrm{O}_{3}: 228.07864$; found: 228.07767 .

(2,5-Dihydroxyphenyl)(3'-methylphenyl)methanone (5). This compound was prepared from $\mathbf{1}$ and 3-methylbenzaldehyde in 34 and 74\% yield following methods A and B, respectively; yellow solid, mp 119-120 ${ }^{\circ} \mathrm{C}$ (lit. [47]: $\left.114-116^{\circ} \mathrm{C}\right)$. IR (KBr) v $v_{\text {máx }} \mathrm{cm}^{-1}: 3285(\mathrm{O}-\mathrm{H}), 1637(\mathrm{C}=\mathrm{O}) ;{ }^{1} \mathrm{H}-\mathrm{NMR}\left(\mathrm{CDCl}_{3}\right)$ : $\delta 2.36(\mathrm{~s}, 3 \mathrm{H}, \mathrm{Me}), 5.82(\mathrm{~s}, 1 \mathrm{H}, 5-\mathrm{OH}), 6.91(\mathrm{~m}, 1 \mathrm{H}, 3-\mathrm{H}$ or $4-\mathrm{H}), 7.01(\mathrm{~m}, 2 \mathrm{H}, 4-\mathrm{H}$ or $3-\mathrm{H}+6-\mathrm{H})$, $7.31\left(\mathrm{~m}, 2 \mathrm{H}, 4{ }^{\prime}-\mathrm{H}+5^{\prime}-\mathrm{H}\right.$ or 5'-H + 6'-H), $7.38\left(\mathrm{~d}, 1 \mathrm{H}, J=7.2 \mathrm{~Hz}, 4^{\prime}-\mathrm{H}\right.$ or 6'-H), $7.41\left(\mathrm{~s}, 1 \mathrm{H}, 2^{\prime}-\mathrm{H}\right)$, 11.63 (s. 1H, 2-OH); ${ }^{13} \mathrm{C}-\mathrm{NMR}\left(\mathrm{CDCl}_{3}\right): \delta 21.4,118.6,118.9,119.1,124.9,126.2,128.2,129.4$, 132.9, 137.6, 138.4, 147.4, 157.0, 201.7; HRMS $\left(\mathrm{M}^{+}\right): \mathrm{m} / z$ calcd for $\mathrm{C}_{14} \mathrm{H}_{12} \mathrm{O}_{3}$ : 228.07864; found: 228.07809 .

(2,5-Dihydroxyphenyl)(4'-methylphenyl)methanone (6). This compound was prepared from $\mathbf{1}$ and 4-methylbenzaldehyde in 58 and $82 \%$ yield following methods A and B, respectively; yellow solid, mp 135-136 ${ }^{\circ} \mathrm{C}$. IR (KBr) v váx cm ${ }^{-1}: 3442(\mathrm{O}-\mathrm{H}), 1629(\mathrm{C}=\mathrm{O}) ;{ }^{1} \mathrm{H}-\mathrm{NMR}\left(\mathrm{CDCl}_{3}\right): \delta 2.40(\mathrm{~s}, 3 \mathrm{H}, \mathrm{Me})$, $5.44(\mathrm{~s}, 1 \mathrm{H}, 5-\mathrm{OH}), 6.93(\mathrm{~d}, 1 \mathrm{H}, J=7.6 \mathrm{~Hz}, 3-\mathrm{H}), 7.02(\mathrm{~m}, 2 \mathrm{H}, 4-\mathrm{H}+6 \mathrm{H}), 7.24(\mathrm{~d}, 2 \mathrm{H}, J=8.1 \mathrm{~Hz}$, $2^{\prime}-\mathrm{H}+3^{\prime}-\mathrm{H}$ or 5'-H + 6'-H), 7.54 (d, 2H, $J=8.1 \mathrm{~Hz}, 3^{\prime}-\mathrm{H}+2^{\prime}-\mathrm{H}$ or 6'H + 5'-H), $11.58(\mathrm{~s}, 1 \mathrm{H}, 2-\mathrm{OH})$; ${ }^{13} \mathrm{C}-\mathrm{NMR}\left(\mathrm{CDCl}_{3}\right): \delta 21.6,118.4,119.0,119.2,124.7,129.1(2 \times \mathrm{C}), 129.4(2 \times \mathrm{C}), 134.9,142.9$, 147.3, 157.0, 201.7; HRMS ( $\left.\mathrm{M}^{+}\right): m / z$ calcd for $\mathrm{C}_{14} \mathrm{H}_{12} \mathrm{O}_{3}: 228.07864$; found: 228.07831 .

(2,5-Dihydroxyphenyl)(3'-methoxyphenyl)methanone (7). This compound was prepared from 1 and 3-methoxybenzaldehyde in 38 and 54\% yield following methods A and B, respectively; yellow solid, mp 97-98 ${ }^{\circ} \mathrm{C}$. IR (KBr) v váx $\mathrm{cm}^{-1}: 3344(\mathrm{O}-\mathrm{H}), 1635(\mathrm{C}=\mathrm{O}) ;{ }^{1} \mathrm{H}-\mathrm{NMR}\left(\mathrm{CDCl}_{3}\right): \delta 3.80(\mathrm{~s}, 3 \mathrm{H}, \mathrm{OMe})$, $5.80(\mathrm{~s}, 1 \mathrm{H}, 5-\mathrm{OH}), 6.91(\mathrm{~d}, 1 \mathrm{H}, J=9.8 \mathrm{~Hz}, 3-\mathrm{H}$ or $4-\mathrm{H}) 7.02(\mathrm{~m}, 2 \mathrm{H}, 4-\mathrm{H}$ or $3-\mathrm{H}+6-\mathrm{H}), 7.06(\mathrm{dd}, 1 \mathrm{H}$, $J=8.2,2.2$, Hz 4'-H or 6'-H), 7.14 (d, 1H, $J=2.2$ Hz 2'-H), 7.16 (d, 1H, $J=7.9 \mathrm{~Hz}, 6{ }^{\prime}-\mathrm{H}$ or 4'-H), 7.32 $(\mathrm{t}, 1 \mathrm{H}, J=7.9 \mathrm{~Hz}, 5 \mathrm{-H}), 11.56$ (s, $1 \mathrm{H}-2-\mathrm{OH}) ;{ }^{13} \mathrm{C}-\mathrm{NMR}\left(\mathrm{CDCl}_{3}\right): \delta 55.5,113.9,118.1,118.4,118.8$, 
119.2, 121.6, 125.1, 129.4, 138.8, 147.5, 157.0, 159.4, 201.2; HRMS $\left(\mathrm{M}^{+}\right): m / z$ calcd for $\mathrm{C}_{14} \mathrm{H}_{12} \mathrm{O}_{4}$ : 244.07356; found: 244.07361 .

(2,5-Dihydroxyphenyl)(4'-methoxyphenyl)methanone (8). This compound was prepared from $\mathbf{1}$ and 4-methoxybenzaldehyde, in 58 and 79\% yield according methods A and B, respectively; yellow solid, mp 144-145 ${ }^{\circ} \mathrm{C}$. IR (KBr) v váx $\mathrm{cm}^{-1}: 3343(\mathrm{O}-\mathrm{H}), 1631(\mathrm{C}=\mathrm{O}) ;{ }^{1} \mathrm{H}-\mathrm{NMR}\left(\mathrm{CDCl}_{3}\right): \delta 3.87(\mathrm{~s}, 3 \mathrm{H}$, OMe), 6.90 (d, 1H, $J=8.8 \mathrm{~Hz}, 3-\mathrm{H}$ or 4-H), 6.97 (d, 2H, $J=8.8 \mathrm{~Hz}, 2^{\prime}-\mathrm{H}+3$ 3'-H $^{\prime}$ or 5'-H + 6'-H), 7.08 $(\mathrm{m}, 2 \mathrm{H}, 4-\mathrm{H}$ or $3-\mathrm{H}+6-\mathrm{H}), 7.72\left(\mathrm{~d}, 2 \mathrm{H}, J=8.8 \mathrm{~Hz}, 66^{\prime}-\mathrm{H}+5^{\prime}-\mathrm{H}\right.$ or 3'-H + 2'-H), 8.32(s, 1H, 5-OH), $11.38(\mathrm{~s}, 1 \mathrm{H}, 2-\mathrm{OH}) ;{ }^{13} \mathrm{C}-\mathrm{NMR}\left(\mathrm{CDCl}_{3}\right): \delta 55.5,113.6,115.9,118.1,118.7,119.2,122.4,124.4,130.4$, 131.8, 148.7, 155.9, 162.8, 199.7; HRMS $\left(\mathrm{M}^{+}\right): \mathrm{m} / z$ calcd for $\mathrm{C}_{14} \mathrm{H}_{12} \mathrm{O}_{4}$ : 244.07356; found: 244.07360 .

(2,5-Dihydroxyphenyl) (2',5'-dimethoxyphenyl)methanone (9). This compound was prepared from 1 and 2,5-dimethoxybenzaldehyde in 70\% yield (method B); yellow solid, mp $135-136{ }^{\circ} \mathrm{C}$. IR $(\mathrm{KBr}) v_{\operatorname{máx}}$ $\mathrm{cm}^{-1}: 3299(\mathrm{O}-\mathrm{H}), 1637(\mathrm{C}=\mathrm{O}) ;{ }^{1} \mathrm{H}-\mathrm{NMR}\left(\mathrm{CDCl}_{3}+\mathrm{DMSO}-d_{6}\right): \delta 3.74(\mathrm{~s}, 3 \mathrm{H}, \mathrm{OMe}), 3.78(\mathrm{~s}, 3 \mathrm{H}$, OMe), 6.82 (s, 2H, 6-H + 6'-H), 6.87 (d, 1H, $J=8.8 \mathrm{~Hz}, 3-\mathrm{H}), 6.96$ (m, 2H, 3'-H + 4'-H), $7.06(\mathrm{~d}, 1 \mathrm{H}$, $J=8.8 \mathrm{~Hz}, 4-\mathrm{H}), 8.39$ (s, $1 \mathrm{H}, 5-\mathrm{OH}), 11.60(\mathrm{~s}, 1 \mathrm{H}, 2-\mathrm{OH}) ;{ }^{13} \mathrm{C}-\mathrm{NMR}\left(\mathrm{CDCl}_{3}+\mathrm{DMSO}-d_{6}\right): \delta 55.9$, 56.4, 113.1, 113.8, 116.0, 116.8, 118.2, 118.4, 119.8, 125.6, 149.1, 150.6, 153.4, 156.3, 201.3; HRMS $\left(\mathrm{M}^{+}\right): \mathrm{m} / \mathrm{z}$ calcd for $\mathrm{C}_{15} \mathrm{H}_{14} \mathrm{O}_{5}: 274.08412$; found: 274.08316 .

(2,5-Dihydroxyphenyl)(3,4-dimethoxyphenyl)methanone (10). This compound was prepared from 1 and 3,4-dimethoxybenzaldehyde in 70\% yield (method B); brown solid, mp 79-81 ${ }^{\circ} \mathrm{C}$. IR ( $\left.\mathrm{KBr}\right) v_{\text {máx }} \mathrm{cm}^{-1}$ : $\left.3354(\mathrm{O}-\mathrm{H}), 1630(\mathrm{C}=\mathrm{O}) ;{ }^{1} \mathrm{H}-\mathrm{NMR}\left(\mathrm{CDCl}_{3}+\mathrm{DMSO}_{-}\right)_{6}\right): \delta 3.86(\mathrm{~s}, 6 \mathrm{H}, 2 \times \mathrm{OMe}), 6.83\left(\mathrm{~s}, 1 \mathrm{H}, 6{ }^{\prime}-\mathrm{H}\right)$, $6.82\left(\mathrm{~s}, 1 \mathrm{H}, 5^{\prime}-\mathrm{H}\right), 6.89$ (d, 1H, $\left.J=9.2 \mathrm{~Hz}, 3-\mathrm{H}\right), 6.94\left(\mathrm{~s}, 1 \mathrm{H}, 2^{\prime}-\mathrm{H}\right), 6.97$ (d, 1H, $\left.J=8.8 \mathrm{~Hz}, 4-\mathrm{H}\right), 7.18$ $(\mathrm{s}, 1 \mathrm{H}, 6-\mathrm{H}), 8.69$ (s, 1H, 5-OH), $11.34(\mathrm{~s}, 1 \mathrm{H}, 2-\mathrm{OH}) ;{ }^{13} \mathrm{C}-\mathrm{NMR}\left(\mathrm{CDCl}_{3}+\mathrm{DMSO}-d_{6}\right): \delta 55.9,60.5$, $104.5,111.2,117.9,118.4,118.8,122.5,124.6,133.0,149.7,149.8,152.8,155.7,200.0$; HRMS (APCI): $[\mathrm{M}+\mathrm{H}]^{+}$calcd for $\mathrm{C}_{15} \mathrm{H}_{14} \mathrm{O}_{5}: 275.08412$; found: 275.09072 .

(2,5-Dihydroxyphenyl)(4'-hydroxy-3'-methoxyphenyl)methanone (11). This compound was prepared in 78\% yield (method B) from 1 and 4-hydroxy-3-methoxybenzaldehyde; yellow solid, mp 221-222 ${ }^{\circ} \mathrm{C}$. IR (KBr) v váx $\mathrm{cm}^{-1}: 3329(\mathrm{O}-\mathrm{H}), 1639(\mathrm{C}=\mathrm{O}) ;{ }^{1} \mathrm{H}-\mathrm{NMR}\left(\mathrm{CDCl}_{3}+\mathrm{DMSO}-d_{6}\right): \delta 3.77$ (s, 3H, OMe), $6.86(\mathrm{~d}, 1 \mathrm{H}, J=8.0 \mathrm{~Hz}, 4-\mathrm{H}$ or $3-\mathrm{H}), 6.95(\mathrm{~d}, 1 \mathrm{H}, J=8.0 \mathrm{~Hz}, 3-\mathrm{H}$ or $4-\mathrm{H}), 7.03(\mathrm{~d}, 1 \mathrm{H}, J=8.8 \mathrm{~Hz}$, 6'-H), $7.11\left(\mathrm{~s}, 1 \mathrm{H}, 2^{\prime}-\mathrm{H}\right), 7.26$ (d, 1H, $\left.J=8.4 \mathrm{~Hz}, 5^{\prime}-\mathrm{H}\right), 7.31$ (s, 1H, 6-H), 7.63 (s, 1H, 4'-OH), 8.89 $(\mathrm{s}, 1 \mathrm{H}, 5-\mathrm{OH}), 11.10(\mathrm{~s}, 1 \mathrm{H}, 2-\mathrm{OH}) ;{ }^{13} \mathrm{C}-\mathrm{NMR}\left(\mathrm{CDCl}_{3}+\mathrm{DMSO}-d_{6}\right): \delta 55.5,107.1,111.5,112.2$, 114.1, 121.7, 123.7, 125.4, 128.5, 143.7, 146.7, 149.7, 156.1, 198.9; HRMS $\left(\mathrm{M}^{+}\right): \mathrm{m} / z$ calcd for $\mathrm{C}_{14} \mathrm{H}_{12} \mathrm{O}_{5}: 260.06847$; found: 260.06764 .

(2,5-Dihydroxyphenyl) (3',4',5'-trimethoxyphenyl)methanone (12). This compound was prepared in $70 \%$ yield (method B) from 1 and 3,4,5-trimethoxybenzaldehyde; yellow solid, mp 68-70 ${ }^{\circ} \mathrm{C}$. IR (KBr) $v_{\text {máx }}$ $\mathrm{cm}^{-1}: 3445(\mathrm{OH}), 3200(\mathrm{O}-\mathrm{H}), 1639(\mathrm{C}=\mathrm{O}) ;{ }^{1} \mathrm{H}-\mathrm{NMR}\left(\mathrm{CDCl}_{3}+\mathrm{DMSO}-d_{6}\right): \delta 3.81(\mathrm{~s}, 9 \mathrm{H}, 3 \times \mathrm{OMe})$, $6.81(\mathrm{~d}, 1 \mathrm{H}, J=8.8 \mathrm{~Hz}, 3-\mathrm{H}), 6.87\left(\mathrm{~s}, 2 \mathrm{H}, 2^{\prime}-\mathrm{H}+6^{\prime}-\mathrm{H}\right), 7.0(\mathrm{~d}, 1 \mathrm{H}, J=8.8 \mathrm{~Hz}, 4-\mathrm{H}), 7.07$ (s, 1H, 6-H), $8.58(\mathrm{~s}, 1 \mathrm{H}, 5-\mathrm{OH}), 11.23(\mathrm{~s}, 1 \mathrm{H}, 2-\mathrm{OH}) ;{ }^{13} \mathrm{C}-\mathrm{NMR}\left(\mathrm{CDCl}_{3}+\mathrm{DMSO}-d_{6}\right): \delta 56.3(2 \times \mathrm{C}), 60.8,107.0$, 117.9, 118.7, 118.8, 124.9, 133.0, 141.3, $149.0(2 \times \mathrm{C}), 149.9,152.8,156.0,199.9 ; \mathrm{HRMS}\left(\mathrm{M}^{+}\right): \mathrm{m} / z$ calcd for $\mathrm{C}_{16} \mathrm{H}_{16} \mathrm{O}_{6}: 304.09469$; found: 304.09378 . 
(2,5-Dihydroxyphenyl)(4'-hydroxy-3',5'-dimethoxyphenyl)methanone (13). This compound was prepared in 70\% (method B) from 1 and 4-hydroxy-3,5-dimethoxybenzaldehyde; yellow solid, $\mathrm{mp}$ 200-201 ${ }^{\circ} \mathrm{C}$. IR (KBr) v váx $\mathrm{cm}^{-1}: 3331(\mathrm{O}-\mathrm{H}), 1635(\mathrm{C}=\mathrm{O}) ;{ }^{1} \mathrm{H}-\mathrm{NMR}\left(\mathrm{CDCl}_{3}+\mathrm{DMSO}-d_{6}\right): \delta 3.92(\mathrm{~s}$, $6 \mathrm{H}, 2 \times \mathrm{OMe}), 6.87$ (d, 1H, $J=9.0 \mathrm{~Hz}, 3-\mathrm{H}), 7.03$ (s, 3H, 6-H + 2'-H + 6'-H), 7,16 (d, 1H, $J=9.0 \mathrm{~Hz}$, $4-\mathrm{H}), 8.47(\mathrm{~s}, 1 \mathrm{H}, 4-\mathrm{OH}), 8.78(\mathrm{~s}, 1 \mathrm{H}, 5-\mathrm{OH}), 11.15(\mathrm{~s}, 1 \mathrm{H}, 2-\mathrm{OH}) ;{ }^{13} \mathrm{C}-\mathrm{NMR}\left(\mathrm{CDCl}_{3}+\mathrm{DMSO}-d_{6}\right): \delta$ $56.0(2 \times \mathrm{C}), 107.2(2 \times \mathrm{C}), 117.3,118.0,118.9,123.5,127.5,139.6,146.8(2 \times \mathrm{C}), 148.6,154.7$, 198.6; HRMS $\left(\mathrm{M}^{+}\right): m / z$ calcd for $\mathrm{C}_{15} \mathrm{H}_{14} \mathrm{O}_{6}$ : 290.07904; found: 290.07830 .

(1,4-Dihydroxynaphthalen-2-yl)(2'-methylphenyl)methanone (14). This compound was prepared from quinone 2 and 2-methylbenzaldehyde in 53 and $82 \%$ yield following methods $\mathrm{A}$ and $\mathrm{B}$, respectively; orange solid, mp $132-133{ }^{\circ} \mathrm{C}$. IR $(\mathrm{KBr}) v_{\text {máx }} \mathrm{cm}^{-1}: 3357(\mathrm{O}-\mathrm{H}), 1638(\mathrm{C}=\mathrm{O}) ;{ }^{1} \mathrm{H}-\mathrm{NMR}\left(\mathrm{CDCl}_{3}\right): \delta$ 2.23 (s, 3H, Me), 5.53 (s, 1H, 4-OH), 6.46 (s, 1H, 3-H), 7.17 (m, 3H, 3'-H + 4'-H + 6'-H), 7.26 (m, 1H, $5 '-\mathrm{H}), 7.58$ (t, 1H, $J=7.6 \mathrm{~Hz}, 6-\mathrm{H}$ or 7-H), $7.66(\mathrm{t}, 1 \mathrm{H}, J=7.6 \mathrm{~Hz}, 7-\mathrm{H}$ or $6-\mathrm{H}), 8.07$ (d, 1H, $J=8.3 \mathrm{~Hz}$, $5-\mathrm{H}$ or $8-\mathrm{H}), 8.50(\mathrm{~d}, 1 \mathrm{H}, J=8.3 \mathrm{~Hz}, 8-\mathrm{H}$ or $5-\mathrm{H}), 13.63(\mathrm{~s}, 1 \mathrm{H}, 1-\mathrm{OH}) ;{ }^{13} \mathrm{C}-\mathrm{NMR}\left(\mathrm{CDCl}_{3}\right): \delta 19.7$, 107.5, 112.4, 121.9, 124.0, 125.4, 125.9, 126.7, 127.0, 129.8, 129.9, 130.3, 130.8, 135.2, 138.0, 143.1, 158.8, 203.7; HRMS (APCI): [M+H] $]^{+}$calcd for $\mathrm{C}_{18} \mathrm{H}_{14} \mathrm{O}_{3}: 279.09429$; found: 279.10136.

(1,4-Dihydroxynaphthalen-2-yl)(3'-methylphenyl)methanone (15). This compound was prepared from quinone 2 and 3-methylbenzaldehyde in 41 and 69\% yield according methods $\mathrm{A}$ and $\mathrm{B}$, respectively; orange solid, mp $154-155^{\circ} \mathrm{C}$. IR ( $\left.\mathrm{KBr}\right) v_{\text {máx }} \mathrm{cm}^{-1}: 3313(\mathrm{O}-\mathrm{H}), 1633(\mathrm{C}=\mathrm{O}) ;{ }^{1} \mathrm{H}-\mathrm{NMR}\left(\mathrm{CDCl}_{3}\right): \delta 2.44$ (s, 3H, Me), 6.98 (s, 1H, 3-H), 7.39 (m, 2H, 4'-H or 6'-H + 2'-H), 7.51 (m, 2H, 6'-H or 4'-H + 5'-H), $7.56(\mathrm{~m}, 1 \mathrm{H}, 6-\mathrm{H}$ or $7-\mathrm{H}), 7.66(\mathrm{t}, 1 \mathrm{H}, J=7.6 \mathrm{~Hz}, 7-\mathrm{H}$ or $6-\mathrm{H}), 8.20(\mathrm{~d}, 1 \mathrm{H}, J=8.3 \mathrm{~Hz}, 5-\mathrm{H}$ or $8-\mathrm{H})$, $8.46(\mathrm{~d}, 1 \mathrm{H}, J=8.3 \mathrm{~Hz}, 8-\mathrm{H}$ or $5-\mathrm{H}), 8.87(\mathrm{~s}, 1 \mathrm{H}, 4-\mathrm{OH}), 13.50(\mathrm{~s}, 1 \mathrm{H}, 1-\mathrm{OH}) ;{ }^{13} \mathrm{C}-\mathrm{NMR}\left(\mathrm{CDCl}_{3}\right): \delta$ 21.4, 107.4, 111.9, 122.3, 124.2, $125.8(2 \times \mathrm{C}), 126.1,127.9,129.3,129.5,130.1,132.0,138.1,138.5$, 144.3, 157.4, 201.2; HRMS (APCI): $[\mathrm{M}+\mathrm{H}]^{+}$calcd for $\mathrm{C}_{18} \mathrm{H}_{14} \mathrm{O}_{3}: 279.09429$; found: 279.10124 .

(1,4-Dihydroxynaphthalen-2-yl)(4'-methylphenyl)methanone (16). This compound was prepared from 2 and 4-methylbenzaldehyde in 57 and 84\% yield according methods A and B, respectively; orange solid, mp 150-151 ${ }^{\circ} \mathrm{C}$. IR (KBr) $v_{\text {máx }} \mathrm{cm}^{-1}: 3422(\mathrm{O}-\mathrm{H}), 1635(\mathrm{C}=\mathrm{O}) ;{ }^{1} \mathrm{H}-\mathrm{NMR}\left(\mathrm{CDCl}_{3}\right): \delta 2.43(\mathrm{~s}, 3 \mathrm{H}$, Me), 7.0 (s, 1H, 3-H), 7.30 (d, 2H, J=7.8 Hz, 2'-H + 3'-H or 5'-H + 6'-H), 7.56 (t, 1H, $J=7.5 \mathrm{~Hz}, 6-\mathrm{H}$ or 7-H), $7.64\left(\mathrm{~d}, 2 \mathrm{H}, J=7.8 \mathrm{~Hz}, 3^{\prime}-\mathrm{H}+2^{\prime}-\mathrm{H}\right.$ or 6'-H + 5'-H), $7.65(\mathrm{~m}, 1 \mathrm{H}, 7-\mathrm{H}$ or 6-H), $8.20(\mathrm{~d}, 1 \mathrm{H}$, $J=8.3 \mathrm{~Hz}, 5-\mathrm{H}$ or $8-\mathrm{H}), 8.47$ (d, 1H, $J=8.3 \mathrm{~Hz}, 8-\mathrm{H}$ or $5-\mathrm{H}), 8.71$ (s, 1H, 4-OH), 13.48 (s, 1H, 1-OH); ${ }^{13} \mathrm{C}-\mathrm{NMR}\left(\mathrm{CDCl}_{3}\right): \delta 21.6,107.6,111.9,122.3,124.2,125.9,126.1,128.9(2 \times \mathrm{C}), 129.3(2 \times \mathrm{C})$, 129.4, 129.9, 135.8, 141.9, 144.2, 157.3, 200.8; HRMS (APCI): $[\mathrm{M}+\mathrm{H}]^{+}$calcd for $\mathrm{C}_{18} \mathrm{H}_{14} \mathrm{O}_{3}$ : 279.09429; found: 279.10122 .

(1,4-Dihydroxynaphthalen-2-yl)(3'-methoxyphenyl)methanone (17). This compound was prepared from 2 and 3-methoxybenzaldehyde in 50 and $71 \%$ yield according methods A and B, respectively; orange solid, mp $149-150{ }^{\circ} \mathrm{C}$ (lit. [34]: 142-144 $\left.{ }^{\circ} \mathrm{C}\right)$. IR (KBr) $v_{\text {máx }} \mathrm{cm}^{-1}: 3344(\mathrm{O}-\mathrm{H}), 1633(\mathrm{C}=\mathrm{O})$; ${ }^{1} \mathrm{H}-\mathrm{NMR}\left(\mathrm{CDCl}_{3}\right): \delta 3.85$ (s, 3H, OMe), 6.99 (s, 1H, 3-H), $7.08\left(\mathrm{dd}, 1 \mathrm{H}, J=8.1,2.0 \mathrm{~Hz}, 4^{\prime}-\mathrm{H}\right.$ or 6'-H), 7.23 (s, 1H, 2'-H), 7.28 (m, 1H, 6'-H or 4'-H), 7.39 (t, 1H, $J=7.9$ Hz, 5'-H), 7.56 (t, 1H, J= 7.6 Hz, 6-H or 7-H), 7.66 (t, $1 \mathrm{H}, J=7.6 \mathrm{~Hz} 7-\mathrm{H}$ or $6-\mathrm{H}), 8.20(\mathrm{~d}, 1 \mathrm{H}, J=8.3 \mathrm{~Hz}, 5-\mathrm{H}$ or $8-\mathrm{H}), 8.47(\mathrm{~d}, 1 \mathrm{H}, J=8.3 \mathrm{~Hz}$ $8-\mathrm{H}$ or $5-\mathrm{H}), 8.65(\mathrm{~s}, 1 \mathrm{H}, 4-\mathrm{OH}), 13.46(\mathrm{bs}, 1 \mathrm{H}, 1-\mathrm{OH}) ;{ }^{13} \mathrm{C}-\mathrm{NMR}\left(\mathrm{CDCl}_{3}\right): \delta 55.5,107.3,111.9$, 
113.7, 117.6, 121.4, 122.3, 124.3, 125.9, 126.2, 129.3, 129.6, 130.1, 139.8, 144.3, 157.7, 159.3, 200.7; HRMS $\left(\mathrm{M}^{+}\right): m / z$ calcd for $\mathrm{C}_{18} \mathrm{H}_{14} \mathrm{O}_{4}: 294.08921$; found: 294.08854 .

(1,4-Dihydroxynaphthalen-2-yl)(4'-methoxyphenyl)methanone (18). This compound was prepared from 2 and 4-methoxybenzaldehyde in 69 and 88\% yield according methods A and B, respectively; yellow solid, mp $150-151^{\circ} \mathrm{C}$ (lit. [34]: $130-132{ }^{\circ} \mathrm{C}$ ). IR (KBr) $v_{\operatorname{máx}} \mathrm{cm}^{-1}: 3470(\mathrm{O}-\mathrm{H}), 1631(\mathrm{C}=\mathrm{O})$; ${ }^{1} \mathrm{H}-\mathrm{NMR}\left(\mathrm{CDCl}_{3}\right): \delta 3.86(\mathrm{~s}, 3 \mathrm{H}, \mathrm{OMe}), 6.97\left(\mathrm{~d}, 2 \mathrm{H}, J=8.7 \mathrm{~Hz}, 2^{\prime}-\mathrm{H}+3{ }^{\prime}-\mathrm{H}\right.$ or $\left.5^{\prime}-\mathrm{H}+66^{\prime}-\mathrm{H}\right), 7.02$ (s, 1H, 3-H), 7.56 (t, 1H, $J=7.4 \mathrm{~Hz}, 6-\mathrm{H}$ or 7-H), 7.65 (t, 1H, $J=7.4 \mathrm{~Hz}, 7-\mathrm{H}$ or 6-H), $7.75(\mathrm{~d}, 2 \mathrm{H}$, $J=8.7 \mathrm{~Hz}, 66^{\prime}-\mathrm{H}+5^{\prime}-\mathrm{H}$ or 3'-H + 2'-H), $8.20(\mathrm{~d}, 1 \mathrm{H}, J=8.3 \mathrm{~Hz}, 5-\mathrm{H}$ or $8-\mathrm{H}), 8.47$ (m, 2H, 8-H or 5-H + 4-OH), $13.43(\mathrm{~s}, 1 \mathrm{H}, 1-\mathrm{OH}) ;{ }^{13} \mathrm{C}-\mathrm{NMR}\left(\mathrm{CDCl}_{3}\right): \delta 55.5,107.8,111.9,113.5,122.3,124.2,125.9$, 126.1, $129.3(2 \times \mathrm{C}), 129.8,130.9,131.6(2 \times \mathrm{C}), 144.1,157.2,162.4,199.6$; HRMS (APCI): [M+H] ${ }^{+}$ calcd for $\mathrm{C}_{18} \mathrm{H}_{14} \mathrm{O}_{4}: 295.08921$; found: 295.08059 .

(1,4-Dihydroxynaphthalen-2-yl)(2',5'-dimethoxyphenyl)methanone (19). This compound was prepared from 2 and 2,5-dimethoxybenzaldehyde in 65\% yield (method B); yellow solid, mp $160-161{ }^{\circ} \mathrm{C}$. IR $(\mathrm{KBr}) v_{\text {máx }} \mathrm{cm}^{-1}: 3389(\mathrm{O}-\mathrm{H}), 1630(\mathrm{C}=\mathrm{O}) ;{ }^{1} \mathrm{H}-\mathrm{NMR}\left(\mathrm{CDCl}_{3}+\mathrm{DMSO}-d_{6}\right): \delta 3.75(\mathrm{~s}, 3 \mathrm{H}, \mathrm{OMe}), 3.79$ (s, 3H, OMe), 6.70 (s, 1H, 6'-H), $6.90(\mathrm{~s}, 1 \mathrm{H}, 3-\mathrm{H}), 6.97$ (m, 2H, 3'-H + 4'-H), 7.56 (t, 1H, J=8.8 Hz, 6-H or 7-H), 7.66 (t, 1H, $J=8.8 \mathrm{~Hz}, 7-\mathrm{H}$ or 6-H), 8.18 (d, 1H, $J=8.4 \mathrm{~Hz}, 8-\mathrm{H}), 8.47$ (s, 1H, 4-OH), $8.48(\mathrm{~d}, 1 \mathrm{H}, J=8.4 \mathrm{~Hz}, 5-\mathrm{H}), 13.48(\mathrm{~s}, 1 \mathrm{H}, 1-\mathrm{OH}) ;{ }^{13} \mathrm{C}-\mathrm{NMR}\left(\mathrm{CDCl}_{3}+\mathrm{DMSO}-d_{6}\right): \delta 56.0,56.6$, 107.4, 113.1, 113.2, 113.9, 117.0, 122.4, 124.5, 125.9, 126.2, 129.1, 129.7, 130.5, 144.4, 150.7, 153.5, 157.4, 200.8; HRMS (M+ $\left.{ }^{+}\right): m / z$ calcd for $\mathrm{C}_{19} \mathrm{H}_{16} \mathrm{O}_{5}$ : 324.09978; found: 324.09914 .

(1,4-Dihydroxynaphthalen-2-yl)(3',4'-dimethoxyphenyl)methanone (20). This compound was prepared from 2 and 3,4-dimethoxybenzaldehyde in 63\% yield (method B); orange solid, mp $212-213{ }^{\circ} \mathrm{C}$. IR $(\mathrm{KBr}) v_{\text {máx }} \mathrm{cm}^{-1}: 3462(\mathrm{O}-\mathrm{H}), 1638(\mathrm{C}=\mathrm{O}) ;{ }^{1} \mathrm{H}-\mathrm{NMR}\left(\mathrm{CDCl}_{3}+\mathrm{DMSO}-d_{6}\right): \delta 3.65(\mathrm{~s}, 6 \mathrm{H}, 2 \times \mathrm{OMe})$, $6.82\left(\mathrm{~s}, 1 \mathrm{H}, 5^{\prime}-\mathrm{H}\right), 6.88\left(\mathrm{~s}, 1 \mathrm{H}, 66^{\prime}-\mathrm{H}\right.$ or 2'-H), $7.00\left(\mathrm{~s}, 1 \mathrm{H}, 2^{\prime}-\mathrm{H}\right.$ or 6'-H), $7.12(\mathrm{~s}, 1 \mathrm{H}, 3-\mathrm{H}), 7.56(\mathrm{~d}, 1 \mathrm{H}$, $J=6.8 \mathrm{~Hz}, 8-\mathrm{H}), 8.19(\mathrm{~d}, 1 \mathrm{H}, J=6.8 \mathrm{~Hz}, 5-\mathrm{H}), 8.46(\mathrm{t}, 2 \mathrm{H}, J=8.4 \mathrm{~Hz}, 6-\mathrm{H}+7-\mathrm{H}), 9.05(\mathrm{~s}, 1 \mathrm{H}$, 4-OH), $13.42(\mathrm{~s}, 1 \mathrm{H}, 1-\mathrm{OH}) ;{ }^{13} \mathrm{C}-\mathrm{NMR}\left(\mathrm{CDCl}_{3}+\mathrm{DMSO}-d_{6}\right): \delta 56.0,60.7,104.7,107.3,111.0,111.8$, $122.3,124.1,126.0,126.7,128.7,129.3,129.9,130.9,144.3,149.8,152.9,157.1$, 199.9; HRMS (APCI): $[\mathrm{M}+\mathrm{H}]^{+}$calcd for $\mathrm{C}_{19} \mathrm{H}_{16} \mathrm{O}_{5}: 325.09977$; found: 325.09146 .

(1,4-Dihydroxynaphthalen-2-yl)(4'-hydroxy-3'-methoxyphenyl)methanone (21). This compound was prepared from 2 and 4-hydroxy-3-methoxybenzaldehyde in 73\% yield (method B); orange solid, mp 221-222 ${ }^{\circ} \mathrm{C}$. IR (KBr) v váx cm ${ }^{-1}: 3469(\mathrm{O}-\mathrm{H}), 1635(\mathrm{C}=\mathrm{O}) ;{ }^{1} \mathrm{H}-\mathrm{NMR}\left(\mathrm{CDCl}_{3}+\mathrm{DMSO}-d_{6}\right): \delta 3.96$ (s, 3H, OMe), $7.00(\mathrm{~d}, 1 \mathrm{H}, J=7.8 \mathrm{~Hz}, 8-\mathrm{H}), 7.13\left(\mathrm{~s}, 1 \mathrm{H}, 2^{\prime}-\mathrm{H}\right), 7.33$ (d, 1H, $\left.J=7.6 \mathrm{~Hz}, 5-\mathrm{H}\right), 7.43$ (s, 1H, 3-H), 7.56 (t, 1H, $J=7.8 \mathrm{~Hz}, 6-\mathrm{H}$ or 7-H), 7.65 (t, 1H, $J=7.8 \mathrm{~Hz}, 7-\mathrm{H}$ or 6-H), $8.20(\mathrm{~d}, 1 \mathrm{H}$, $J=8.0 \mathrm{~Hz}, 66^{\prime}-\mathrm{H}$ or 5'-H), $8.44\left(\mathrm{~d}, 1 \mathrm{H}, J=8.0 \mathrm{~Hz}, 5^{\prime}-\mathrm{H}\right.$ o $\left.6^{\prime}-\mathrm{H}\right), 8.81$ (s, 1H, 4'-OH), $9.04(\mathrm{~s}, 1 \mathrm{H}$, 4-OH), $13.38(\mathrm{~s}, 1 \mathrm{H}, 1-\mathrm{OH}) ;{ }^{13} \mathrm{C}-\mathrm{NMR}\left(\mathrm{CDCl}_{3}+\mathrm{DMSO}-d_{6}\right): \delta 55.9,107.5,112.0,112.6,114.5,122.1$, 123.9, 124.1, 125.7, 125.8, 128.9, 129.5, 129.7, 144.1, 147.1, 150.1, 156.5, 199.3; HRMS $\left(\mathrm{M}^{+}\right): \mathrm{m} / \mathrm{z}$ calcd for $\mathrm{C}_{18} \mathrm{H}_{14} \mathrm{O}_{5}: 310.08413$; found: 310.08401 . 
(1,4-Dihydroxynaphthalen-2-yl)(3',4',5'-trimethoxyphenyl)methanone (22). This compound was prepared from 2 and 3,4,5-trimethoxybenzaldehyde in 60\% yield (method B); brown solid, mp 189-191 ${ }^{\circ} \mathrm{C}$. Mp and the spectral properties of 22 were in agree to those reported in literature [19].

(1,4-Dihydroxynaphthalen-2-yl)(4'-hydroxy-3',5'-dimethoxyphenyl)methanone (23). This compound was prepared from 2 and 4-hydroxy-3,5-dimethoxybenzaldehyde in 66\% yield (method B); yellow solid, mp 173-174 ${ }^{\circ} \mathrm{C}$. IR (KBr) $v_{\text {máx }} \mathrm{cm}^{-1}: 3346(\mathrm{O}-\mathrm{H}), 1630(\mathrm{C}=\mathrm{O}) ;{ }^{1} \mathrm{H}-\mathrm{NMR}\left(\mathrm{CDCl}_{3}+\mathrm{DMSO}-d_{6}\right)$ : $\delta 3.95(\mathrm{~s}, 6 \mathrm{H}, 2 \times \mathrm{OMe}), 7.08\left(\mathrm{~s}, 2 \mathrm{H}, 2^{\prime}-\mathrm{H}+6^{\prime}-\mathrm{H}\right), 7.16(\mathrm{~s}, 1 \mathrm{H}, 3-\mathrm{H}), 7.56(\mathrm{t}, 1 \mathrm{H}, J=7.2 \mathrm{~Hz}, 6-\mathrm{H}$ or 7-H), 7.66 (t, 1H, $J=7.2 \mathrm{~Hz}, 7-\mathrm{H}$ or $6-\mathrm{H}), 8.20$ (d, 1H, $J=8.4 \mathrm{~Hz}, 8-\mathrm{H}), 8.45$ (d, 1H, $J=8.4 \mathrm{~Hz}, 5-\mathrm{H})$, $9.11(\mathrm{~s}, 2 \mathrm{H}, 4-\mathrm{OH}), 13.34(\mathrm{~s}, 1 \mathrm{H}, 1-\mathrm{OH}) ;{ }^{13} \mathrm{C}-\mathrm{NMR}\left(\mathrm{CDCl}_{3}+\mathrm{DMSO}-d_{6}\right): \delta 56.3(2 \times \mathrm{C}), 107.2$ $(2 \times \mathrm{C}), 111.8,122.1,122.5,123.9,125.7,125.9,128.6,129.0,129.5,139.0,144.2,146.9,(2 \times \mathrm{C})$, 149.3, 199.2; HRMS ( $\left.\mathrm{M}^{+}\right): m / z$ calcd for $\mathrm{C}_{19} \mathrm{H}_{16} \mathrm{O}_{6}$ : 340.09469; found: 340.09380 .

\subsection{Antiproliferative Assay}

\subsubsection{Cell Lines and Culture Conditions}

Human cancer cell lines (T24, DU-145, MCF7) were cultured in high-glucose Dulbecco's modified Eagle medium (Gibco, Grand Island, NY, USA) supplemented with 10\% foetal calf serum, penicillin (100 U/mL), and streptomycin $(100 \mu \mathrm{g} / \mathrm{mL})$. Balb/3T3 cells (normal mouse fibroblasts) were cultured in the same medium, except that the foetal calf serum was replaced by $10 \%$ newborn calf serum. All cultures were kept at $37{ }^{\circ} \mathrm{C}$ in $95 \%$ air $/ 5 \% \mathrm{CO}_{2}$ at $100 \%$ humidity. Phosphate-buffered saline (PBS) was purchased from Gibco. Cells were incubated at the indicated times at $37{ }^{\circ} \mathrm{C}$ with or without hydroquinones at various concentrations.

\subsubsection{Cellular Assays}

The cytotoxicity of the bis aryl ketones was assessed by following the reduction of MTT (3-(4,5-dimethylthiazolyl-2)-2,5-diphenyltetrazolium bromide) to formazan blue [37]. Briefly, cells were seeded into 96-well plates at a density of 10,000 cells/well for $24 \mathrm{~h}$ and then incubated for $48 \mathrm{~h}$ with or without the compounds. Cells were then washed twice with warm PBS and incubated with MTT $(0.5 \mathrm{mg} / \mathrm{mL})$ for $2 \mathrm{~h}$ at $37{ }^{\circ} \mathrm{C}$. Incubation medium was thereafter discarded and the blue formazan crystals were solubilized by adding $100 \mu \mathrm{L}$ DMSO/well. The colour solution was subsequently read at $550 \mathrm{~nm}$. Results are expressed as \% of MTT reduction compared to untreated control conditions. The calculation of $\mathrm{EC}_{50}$ values was performed by using GraphPad Prism software (San Diego, CA, USA).

\section{Conclusions}

We have extended the photo-Friedel Crafts acylation of 1,4-benzo- and 1,4-naphthoquinone with aldehydes to the synthesis of a significant number of oxygen-substituted diaryl ketones. The main advantages of this general procedure respect to other methods to construct oxygen-substituted diaryl ketone framework are the atom economy, simplicity, cheap and the chemical stability of the oxygen substituent of precursors and/or products. From the antiproliferative screening of the oxygen-substituted 
diaryl ketones, compounds 12 and $\mathbf{2 2}$ stand out by their biological activity levels on prostate DU-145 $\left(\mathrm{EC}_{50}: 1.2\right.$ and $\left.5.9 \mu \mathrm{M}\right)$ and bladder $\mathrm{T} 24\left(\mathrm{EC}_{50}: 3.6\right.$ and $\left.13.5 \mu \mathrm{M}\right)$ cell lines, compared to those of the anticancer drug mitomycin $\mathrm{C}\left(\mathrm{EC}_{50}: 14.3\right.$ and $\left.42.2 \mu \mathrm{M}\right)$. Even though compound 22 displayed less potency than the analog 12, it exhibited a better mean selective index. Although compounds 12 and 22 have $\mathrm{EC}_{50}$ values lower than to $\mathrm{GI}_{50}$ values reported for phenstatin, due to their structural similarity it may be hypothesized that inhibition of microtubule assembly is involved in the antiproliferative mechanism of these two compounds. Chemical modifications of compounds $\mathbf{1 2}$ and 22 directed to access to the scaffold of future active tubulin polymerization inhibitors are in progress.

\section{Supplementary Materials}

Supplementary materials can be accessed at: http://www.mdpi.com/1420-3049/18/8/9818/s1.

\section{Acknowledgments}

We thank the Fondo Nacional de Ciencia y Tecnología, Chile (Grant NO. 1100376), the Fonds Spéciaux de Recherche (FSR), Université catholique de Louvain, Belgium, and the FNRS (FRFC Grant 2.4555.08) for financial support to this study. The authors are grateful to Véronique Allaeys and Isabelle Blave for their excellent technical assistance.

\section{Conflicts of Interest}

The authors declare no conflict of interest.

\section{References}

1. Thompson, R.H. Naturally Occurring Quinones III, Recent Advances. Chapman and Hall: London, UK, 1987.

2. Maruyama, K.; Naruta, Y. Syntheses of alpha- and beta-lapachones and their homologues by way of photochemical side chain introduction to quinone. Chem. Lett. 1977, 8, 847-850.

3. Uno, H. Allylation of 2-alkanoyl 1,4-quinones with allylsilanes and allylstannanes. Efficient synthesis of pyranonaphthoquinone antibiotics. J. Org. Chem. 1986, 51, 350-358.

4. Brimble, M.A.; Lynds, S.M. A short synthesis of deoxyfrenolicin. J. Chem. Soc. Perkin. Trans. 1 1994, 1, 493-496.

5. Kraus, G.A.; Maeda, H. A direct preparation of 1,4-benzodiazepines. The synthesis of medazepam and related compounds via a common intermediate. Tetrahedron Lett. 1994, 35, 9189-9190.

6. Waske, P.A.; Mattay, J.; Oelgemöller, M. Photoacylations of 2-substituted 1,4-naphthoquinones: A concise access to biologically active quinonoid compounds. Tetrahedron Lett. 2006, 47, 1329-1332.

7. Valderrama, J.A.; Pessoa-Mahana, D.; Tapia, R.A.; Rojas de Arias, A.; Nakayama, H.; Torres, S.; Miret, J.; Ferreira, M.E. Studies on quinones. Part 34: The reaction of styrene with activated 1,4-benzoquinones: Access to potential antiprotozoal pyranobenzoquinones. Tetrahedron 2001, $57,8653-8658$. 
8. Valderrama, J.A.; Benites, J.; Cortés, M.; Pessoa-Mahana, D.; Prina, E.; Fournet, A. Studies on quinones. Part 35: Access to antiprotozoal active euryfurylquinones and hydroquinones. Tetrahedron 2002, 58, 881-886.

9. Valderrama, J.A.; Zamorano, C.; González, M.F.; Prina, E.; Fournet, A. Studies on quinones. Part 39: Synthesis and leishmanicidal activity of acylchloroquinones and hydroquinones. Bioorg. Med. Chem. 2005, 13, 4153-4159.

10. Valderrama, J.A.; González, M.F.; Pessoa-Mahana, D.; Tapia, R.A.; Fillion, H.; Pautet, F.; Rodríguez, J.A.; Theoduloz, C.; Schmeda-Hishmann, G. Studies on quinones. Part 41: Synthesis and cytotoxicity of isoquinoline-containing polycyclic quinones. Bioorg. Med. Chem. 2006, 14, 5003-5011.

11. Valderrama, J.A.; González, M.F.; Colonelli, P.; Vásquez, D. Design and synthesis of angucyclinone 5-aza analogues. Synlett 2006, 17, 2777-2780.

12. Valderrama, J.A.; Vásquez, D. Design and synthesis of angucyclinone AB-pyrido[2,3- $d$ ]pyrimidine analogues. Tetrahedron Lett. 2008, 49, 703-706.

13. Vásquez, D.; Rodríguez, J.A.; Theoduloz, C.; Buc Calderon, P.; Valderrama, J.A. Studies on quinones. Part 46. Synthesis and in vitro antitumor evaluation of aminopyrimidoisoquinolinequinones. Eur. J. Med. Chem. 2010, 45, 5234-5242.

14. Valderrama, J.A.; Ibacache, A.; Rodriguez, J.A.; Theoduloz, C.; Benites, J. Studies on Quinones. Part 47. Synthesis of novel phenylaminophenanthridinequinones as potential antitumor agents. Eur. J. Med. Chem. 2011, 46, 3398-3409.

15. Vásquez, R.; Verrax, J.; Valderrama, J.A.; Buc Calderon. P. Aminopyrimidoisoquinolinequinone (APIQ) redox cycling is potentiated by ascorbate and induces oxidative stress leading to necroticlike cancer cell death. Invest. New Drug. 2012, 30, 1003-1011.

16. Monsalve, F.A.; Valderrama, J.A.; Vásquez, D.; Ibacache, A.; Rodríguez, J.A., González, D.R.; González. E. Inhibition of human topoisomerase I and activation of caspase-3 by aza-angucyclinones and arylaminopyrimido[4,5-c]isoquinoline-7,10-quinones. Int. J. Mol. Med. 2012, 30, 151-156.

17. Kviecinski, M.R.; Pedrosa, R.C.; Felipe, K.B.; Farias, M.S.;Glorieux, C.; Valenzuela, M.; Sid, B.; Benites, J.; Valderrama, J.A.; Verrax, J.; et al. Inhibition of cell proliferation and migration by oxidative stress from ascorbate-driven juglone redox cycling in human bladder-derived T24 cells. Biochem. Biophys. Res. Commun. 2012, 421, 268-273.

18. Delgado, V.; Ibacache, A.; Theoduloz, C.; Valderrama J.A. Synthesis and in vitro cytotoxic evaluation of aminoquinones structurally related to marine isoquinolinequinones. Molecules 2012, 17, 7042-7056.

19. Iribarra, J,: Vásquez, D.; Theoduloz, C.; Benites, J.; Ríos, D.; Valderrama, J.A. Synthesis and antitumor evaluation of 6-arylsubstituted benzo[j]phenanthridine- and benzo[ $g]$ pyrimido[4,5-c] isoquinolinequinones. Molecules 2012, 17, 11616-11629.

20. Ríos, D.; Benites, J.; Valderrama, J.A.; Farias, M.; Pedrosa R.C.; Buc Calderon, P.; Verrax, J. Biological evaluation of 3-acyl-2-arylamino-1,4-naphthoquinones as inhibitors of Hsp90 chaperoning function. Curr. Top. Med. Chem. 2012, 12, 2094-2102.

21. Naeimi, H.; Moradi, L. Microwave assisted direct ortho-acylation of phenol and naphthol derivatives by $\mathrm{BF}_{3} \cdot\left(\mathrm{C}_{2} \mathrm{H}_{5}\right)_{2} \mathrm{O}$. Bull. Chem. Soc. Jpn. 2005, 78, 284-287. 
22. Trost, B.M.; Saulnier, M.G. Regioselectivity in lithiation of $t$-butyldimethylsiloxy-3,5dimethoxybenzene. A synthesis of the trimethyl ether of sophoraflavanone A. Tetrahedron Lett. 1985, 26, 123-126.

23. Crombie, L.; Jones, R.C.F.; Palmer, C.J. Synthesis of the insecticidal 1'-acetoxy-mammeins and surangin B. Tetrahedron Lett. 1985, 26, 2933-2936.

24. Duplais, C.; Bures, F.; Sapountzis, I.; Korn, T.J.; Cahiez, G.; Knochel, P. An efficient synthesis of diaryl ketones by iron-catalyzed arylation of aroyl cyanides. Angew. Chem. Int. Ed. Engl. 2004, 43, 2968-2970.

25. Satori, G.; Casnati, G.; Bigi, F. Predieri, G. Ortho-coordinated acylation of phenol systems. J. Org. Chem. 1990, 55, 4371-4377.

26. Boyer, J.L.; Krum, J.E.; Myers, M.C.; Fazal, A.N.; Wigal, C.T. Synthetic utility and mechanistic implications of the Fries rearrangement of hydroquinone diesters in boron trifluoride complexes. J. Org. Chem. 2000, 65, 4712-4714.

27. Klinger, H.; Kolvenbach, W. Die bildung von acetohydrochinon aus acetaldehyd und benzochinon im sonnenlicht. Ber. Dtsch. Chem. Ges. 1898, 31, 1214-1216.

28. Patai, S. The Chemistry of the Quinoid Compounds, Part 1. John Wiley and Sons: New York, NY, USA, 1974; Vol. 1, p. 503.

29. Kraus, G.A.; Liu, P. Benzophenone-mediated conjugate additions of aromatic aldehydes to quinones. Tetrahedron Lett. 1994, 35, 7723-7726.

30. Oelgemöller, M.; Schiel, C.; Fröhlich, R.; Mattay, J. The photo-Friedel-Crafts acylation of 1,4-naphthoquinones. Eur. J. Org. Chem. 2002, 15, 2465-2474.

31. Oelgemöller, M.; Jung, C.; Ortner, J.; Mattay, J.; Schiel, C.; Zimmermann, E. "Green photochemistry" with moderately concentrated sunlight. Spectrum 2005, 18, 28-33.

32. Murphy, B.; Goodrich, P.; Hardacre, C.; Oelgemöller, M. Green photochemistry: Photo-FriedelCrafts acylations of 1,4-naphthoquinone in room temperature ionic liquids. Green Chem. 2009, 11, 1867-1870.

33. Benites, J.; Ríos, D.; Díaz, P.; Valderrama, J.A. The solar-chemical photo-Friedel-Crafts heteroacylation of 1,4-quinones. Tetrahedron Lett. 2011, 52, 609-611.

34. De Leon, F.; Kalagara, S.; Navarro, A.A.; Mito, S. Synthesis of 6-acyl-5,8-quinolinediols by Photo-Friedel-Crafts acylation using sunlight. Tetrahedron Lett. 2013, 54, 3147-3149.

35. Pettit, G.R.; Toki, B.; Herald, D.L.; Verdier-Pinard, P.; Boyd, M.R.; Hamel, E.; Pettit, R.K. Antineoplastic agents. 379. Synthesis of phenstatin phosphate. J. Med. Chem. 1998, 41, 1688-1698.

36. Alvarez, C.; Alvarez, R.; Corchete, P.; Pérez-Melero, C.; Peláez, R.; Medarde, M. Synthesis and biological activity of naphthalene analogues of phenstatins: Naphthylphenstatins. Bioorg. Med. Chem. Lett. 2007, 17, 3417-3420.

37. Mosmann, T. Rapid colorimetric assay for cellular growth and survival: application to proliferation and cytotoxicity assays. J. Immunol. Methods 1983, 65, 55-63.

38. Cushman, M.; Nagarathnam, D.; Gopal, D.; Chakraborti, A.K.; Lin, C.M.; Hamel, E. Synthesis and evaluation of stilbene and dihydrostilbene derivatives as potential anticancer agents that inhibit tubulin polymerization. J. Med. Chem. 1991, 34, 2579-2588. 
39. Pettit, G.R.; Grealish, M.P.; Jung, M.K.; Hamel, E.; Pettit, R.K.; Chapuis, J.C.; Schmidt, J.M. Antineoplastic agents. 465. Structural modification of resveratrol: sodium. Resverastatin phosphate. J. Med. Chem. 2002, 45, 2534-2542.

40. Liou, J.P.; Chang, Y.L.; Kuo, F.M.; Chang, C.W.; Tseng, H.Y.; Wang, C.C.; Yang, Y.N.; Chang, J.Y.; Lee, S.J.; Hsieh, H.P. Concise synthesis and structure-activity relationships of combretastatin A-4 analogues, 1-aroylindoles and 3-aroylindoles, as novel classes of potent antitubulin agents.J. Med. Chem. 2004, 47, 4247-4257.

41. Tron, G.C.; Pirali, T.; Sorba, G.; Pagliai, F.; Busacca, S.; Genazzani, A.A. Medicinal chemistry of combretastatin A4: Present and future directions. J. Med. Chem. 2006, 49, 3033-3044.

42. Romagnoli, R.; Baraldi, P.G.; Carrion, M.D.; Lopez Cara, C.; Preti, D.; Fruttarolo, F.; Pavani, M. G.; Tabrizi, M.A.; Tolomeo, M.; Grimaudo, S.; et al. Synthesis and biological evaluation of 2 - and 3-aminobenzo[ $[b]$ thiophene derivatives as antimitotic agents and inhibitors of tubulin polymerization. J. Med. Chem. 2007, 50, 2273-2277.

43. Hu, L.; Jiang, J.D.; Qu, J.; Li, Y.; Jin, J.; Li, Z.R.; Boykin, D.W. Novel potent antimitotic heterocyclic ketones: Synthesis, Antiproliferative activity, and structure-activity relationships. Bioorg. Med. Chem. Lett. 2007, 17, 3613-3617.

44. Ty, N.; Kaffy, J.; Arrault, A.; Thoret, S.; Pontikis, R.; Dubois, J.; Morin-Allory, L.; Florent, J.C. Synthesis and biological evaluation of cis-locked vinylogous combretastatin-A4 analogues: Derivatives with a cyclopropyl-vinyl or a cyclopropyl-amide bridge. Bioorg. Med. Chem. Lett. 2009, 19, 1318-1322.

45. Ghinet, A.; Rigo, B.; Hénichart, J.P.; Le Broc-Ryckewaert, D.; Pommery, J.; Pommery, N.; Thuru, X.; Quesnel, B.; Gautret, P. Synthesis and biological evaluation of phenstatin metabolites. Bioorgn. Med. Chem. 2011, 19, 6042-6054.

46. Bogert, M.T.; Howells, H.P. The chemistry of the acyl para-quinones. A contribution to the solution of the "Pechmann dyes" problem. J. Am. Chem. Soc. 1930, 52, 837-850.

47. Abdulla, K.A.; Abdul-Rahman, A.L.; Al-Hamdany, R.; Al-Saigh, Z. Preparation and light induced reactions of substituted 1,4-benzoquinones. J. Prakt. Chem. 1982, 34, 498-504.

Sample Availability: Samples of the compounds are available from the authors.

(C) 2013 by the authors; licensee MDPI, Basel, Switzerland. This article is an open access article distributed under the terms and conditions of the Creative Commons Attribution license (http://creativecommons.org/licenses/by/3.0/). 